\title{
EFFORTS TO IMPROVE BASIC MOTION CAPABILITIES NON- LOCOMOTOR FOR DOUBLE HANDICAP STUDENT USING ADAPTIVE GAME APPLICATION
}

\author{
${ }^{1 *}$ Silmi Forestry, ${ }^{2}$ Abdul Salim, ${ }^{3}$ Sunardi \\ 1, 2, 3 Magister Pendidikan Luar Biasa, Universitas Sebelas Maret, Indonesia
}

\begin{abstract}
The purpose of this study was to improve non-locomotor basic movement capability by applying adaptive games for multiple handicapped students of Class IV SLB A YKAB Surakarta in 2015. The method used in this study was experimental method using single subject research (SSR). Subject is multiple handicapped of blind and celebral palsy spectrum. This study employed A-B-A design involving three stages. The first was deciding baseline 1; the second was giving intervention; and the last was measuring the baseline 2. The data were colected through observations and analyzed using the analysis technique of descriptive qualitative data. The results of this study indicated that the scores got from observations were improved. The improvement was showed by the measurement of baseline 1 in which the average score was 57.8, then after the intervention of applying adaptive games, the average score was improved to 81.56. Moreover, the average score from baseline 2 which was not given any intervention was78.75. Based on the results of this study, the application of adaptive games can improve non-locomotor basic movement capability on multiple handicapped students of Class IV SLB A YKAB Surakarta in 2015.
\end{abstract}

Keywords: adaptive games; non-locomotor basic movement capability; multiple handicap

\section{Latar Belakang}

Pendidikan berperan dalam menentukan keberhasilan suatu bangsa. Pendidikan yang baik harus mempunyai tujuan yang jelas. Tujuan pendidikan diantaranya membentuk mental dan karakter seseorang. Seperti yang tertuang dalam Undang-undang no. 20, Tahun 2003, pasal 3 menyebutkan "pendidikan nasional berfungsi mengembangkan kemampuan dan membentuk watak serta peradaban bangsa yang bermartabat dalam rangka mencerdaskan kehidupan bangsa, bertujuan untuk berkembangnya potensi peserta didik agar menjadi manusia ya]ng beriman dan bertakwa kepada Tuhan Yang Maha Esa,

* Corresponding author: Silmi Forestry

silmiforestry91@gmail.com

Published online at http://IJDS.ub.ac.id/

Copyright @ 2018PSLD UB Publishing. All Rights Reserved berakhlak mulia, sehat, berilmu, cakap, kreatif, mandiri dan menjadi warga negara yang demokratis serta bertanggung jawab". Dalam pendidikan diberikan tuntutan oleh pendidik kepada peserta didik untuk mengoptimalkan pertumbuhan dan perkembangan mereka. Oleh karena itu, sebelum pendidik menyelenggarakan pembelajaran harus memperhatikan tujuan yang akan dicapai oleh peserta didik sesuai tugas-tugas perkembangan dan pertumbuhan mereka. Rifa'I \& Anni (2009) berpendapat, "tujuan pembelajaran hendaknya menyatakan apa yang peserta didik mampu lakukan dan apa yang akan peserta didik itu lakukan jika mereka diberikan kesempatan" (hlm. 3).

Pada waktu pendidik merumusakan tujuan pembelajaran, mereka menggunakan informasi mengenai karakteristik peserta didik. Setiap peserta didik mempunyai karakteristik yang 
berbeda antara anak normal dengan anak berkebutuhan khusus (ABK). Salah satu bagian dari anak berkebutuhan khusus adalah tunaganda. Tunaganda merupakan istilah yang digunakan untuk individu yang mengalami spectrum dari beberapa ketunaan, dan baru-baru ini muncul istilah baru yaitu tuna majemuk. Karena tunaganda mempunyai spectrum dari beberapa ketunaan maka permasalahan yang dialami tunaganda jauh lebih komplek jika dibandingkan dengan seseorang yang mengalami ketunaan tunggal. Jenis spectrum ketunaan juga mempengaruhi permasalahan apa yang akan dialami anak tunaganda. Hambatan yang nampak jelas pada tunaganda spectrum tunanetra dan celebral palsy adalah hambatan dalam gerak. Hambatan gerak tubuh yang biasanya dialami oleh anak usia Sekolah Dasar adalah hambatan dalam gerak dasarnya.

Kemampuan gerak dasar dibagi menjadi tiga kategori yaitu: kemampuan lokomotor, kemampuan non lokomotor dan manipulatif (Supena, 2014: 52). Kemampuan non lokomotor dilakukan ditempat yang terdiri dari menekuk dan mengangkat dan menurunkan, melipat dan

memutar, mengocok, melingkar, melambungkan dan lain-lain. Karena permasalahan peserta didik tunaganda sangatlah komplek terutama peserta didik tunaganda dengan spectrum tunanetra dan celebral palsy yang mempunyai hambatan pada gerak dasar non lokomotor, maka dalam proses belajar di sekolah perlu dilakukan penyesuaian dan beberapa pengadaan terhadap fasilitas.

Penyesuaian tersebut juga perlu dilaksanakan dalam Pendidikan Jasmani Olahraga dan Kesehatan yang merupakan bagian integral dari pendidikan secara umum. Hambatan dan gangguan kemampuan gerak dasar non lokomotor yang dimiliki peserta didik tunaganda menyebabkannya tidak mampu mengikuti program pendidikan jasmani secara utuh yang ada di sekolah. Sehingga dalam rangka memberikan pelayanan pendidikan yang tidak diskriminatif maka dibutuhkan beberapa penyesuaian (adaptasi) dalam mata pelajaran pendidikan jasmani. Pelaksanaan pendidikan jasmani yang disesuaikan dengan jenis dan kebutuhan khusus peserta didik disebut sebagai pendidikan jasmani adaptif. Menurut Hendrayana, Pendidikan jasmani adaptif adalah pendidikan jasmani yang diadaptasikan dan atau dimodifikasi untuk memudahkan peserta didik berkebutuhan khusus berpartisipasi aktif dalam pembelajaran pendidikan jasmani peserta didik di sekolah (2013).

Hasil observasi peneliti di SLB A YKAB Surakarta menunjukkan bahwa siswa tunaganda dengan spectrum tunanetra dan celebral palsy kelas IV, mempunyai hambatan gerak dasar non lokomotor yaitu dalam meregangkan jari dan menggenggam. Hambatan gerak tersebut terlihat jelas ketika penulis melakukan pengamatan saat siswa belajar bina diri yaitu keterampilan menggosok gigi, jari jemari siswa nampak kaku ketika memegang sikat dan mengalami kesulitan dalam menggosok gigi. Peneliti juga mengamati ketika pelajaran olahraga, peserta didik tunaganda mengalami kesulitan yang sama. Padahal biasanya anak usia SD memiliki kemampuan gerak dasar non lokomotor seperti merenggangkan jari dan menggenggam yang baik.

Peneliti juga mengamati ketika proses belajar mengajar berlangsung. Sebenarnya guru sudah menggunakan beberapa media dalam pelajaran, tapi dalam penggunaan media tersebut dirasa kurang optimal membantu kemampuan gerak dasar anak dalam merenggangkan jari dan menggenggam. Sehingga dibutuhkan media lain yang menarik dan menyenangkan untuk melatih kemampuan jarinya dalam merenggang dan menggenggam.

Rumusan permasalahan dalam penelitian ini adalah apakah aplikasi 
permainan adaptif dapat meningkatkan kemampuan gerak dasar non lokomotor pada siswa tunaganda kelas IV SLB A YKAB Surakarta tahun pelajaran 2014/2015. Sedangkan tujuan untuk meningkatkan kemampuan gerak dasar non lokomotor melalui aplikasi permainan adaptif pada siswa tunaganda kelas IV SLB A YKAB Surakarta tahun ajaran 2014/2015.

\section{Metode}

Penelitian ini dilaksanakan di SLB/A YKAB Surakarta. Penelitian ini menggunakan jenis pendekatan penelitian eksperimen dengan desain Single Subject Research (SSR) model A-B-A. Langkah pertama pada desain A-B-A adalah mengumpulkan data target behavior sebelum diberikan intervensi pada kondisi baseline pertama (A1). Setelah data menjadi stabil pada kondisi baseline, intervensi (B1) diberikan. Pengumpulan data pada kondisi intervensi dilaksanakan secara kontinyu sampai data mencapai trend dan level yang jelas. Intervensi berupa pemberian permainan adaptif. Kemudian dilakukan pengukuran baseline kedua (A2), penambahan kondisi baseline yang kedua (A2) ini dimaksudkan sebagai kontrol untuk fase intervensi sehingga memungkinkan untuk menarik kesimpulan adanya hubungan fungsional antara variabel bebas dan variabel terikat (Sunanto, 2005:59). Subjek dalam penelitian ini adalah seorang siswi tunaganda dengan spectrum tunanetra dan celebral palsy kelas IV SD di SLB/A YKAB Surakarta.

Teknik pengumpulan data yang digunakan dalam penelitian ini adalah observasi. Observasi dilakukan peneliti untuk mengumpulkan data mengenai perilaku dan proses kerja subjek. Hal ini dapat dikaitkan dengan kesimpulan seorang peneliti yang menyatakan "observasi merupakan suatu proses yang kompleks, suatu proses yang tersusun dari berbagai proses biologis dan psikologis" (Sugiyono, 2010: 203). Oleh karena itu, dalam kegiatan

observasi, pengumpulan data harus berdasarkan proses yang disesuaikan dengan tujuan diadakannya observasi.

Analisis data yang digunakan dalam penelitian ini menggunakan deskriptif komparatif dengan membandingkan data baseline dengan data intervensi berbentuk deskripsi yang kemudian digambarkan dalam bentuk grafik.

\section{Hasil}

Hasil penelitian meliputi data nilai dan rerata yang dapat dilihat pada tabel dan grafik berikut:

Tabel 1. Nilai Baseline 1

\begin{tabular}{|c|c|c|c|}
\hline \multirow[b]{2}{*}{ Sesi } & \multicolumn{3}{|c|}{$\begin{array}{l}\text { Nilai Baseline } 1 \text { (A1) dengan } \\
\text { Standar } 100\end{array}$} \\
\hline & $\begin{array}{c}\text { Penilai } \\
1\end{array}$ & $\begin{array}{c}\text { Penilai } \\
2\end{array}$ & $\begin{array}{l}\text { Rata- } \\
\text { rata }\end{array}$ \\
\hline 1 & 50 & 56,25 & 53,12 \\
\hline 2 & 56,25 & 62,5 & 59,37 \\
\hline 3 & 62,5 & 62,5 & 62,5 \\
\hline 4 & 56,25 & 62,5 & 59,37 \\
\hline 5 & 50 & 56,25 & 53,12 \\
\hline Rata & & & 57,5 \\
\hline
\end{tabular}

Tabel 2 Nilai Intervensi

\begin{tabular}{cccc}
\hline \multirow{2}{*}{ Sesi } & \multicolumn{3}{c}{ Nilai Intervensi dengan Standar 100 } \\
\cline { 2 - 4 } & Penilai 1 & Penilai 2 & Rata-rata \\
\hline 1 & 75 & 75 & 75 \\
2 & 87,5 & 81,25 & 84,37 \\
3 & 81,25 & 75 & 78,12 \\
4 & 75 & 75 & 75 \\
5 & 81,25 & 87,5 & 84,37 \\
6 & 75 & 68,75 & 71,87 \\
7 & 87,5 & 87,5 & 87,5 \\
8 & 87,5 & 87,5 & 87,5 \\
9 & 87,5 & 81,25 & 84,37 \\
10 & 81,25 & 87,5 & 84,37 \\
\hline Rata-rata & \multicolumn{3}{c}{81,25} \\
\hline
\end{tabular}




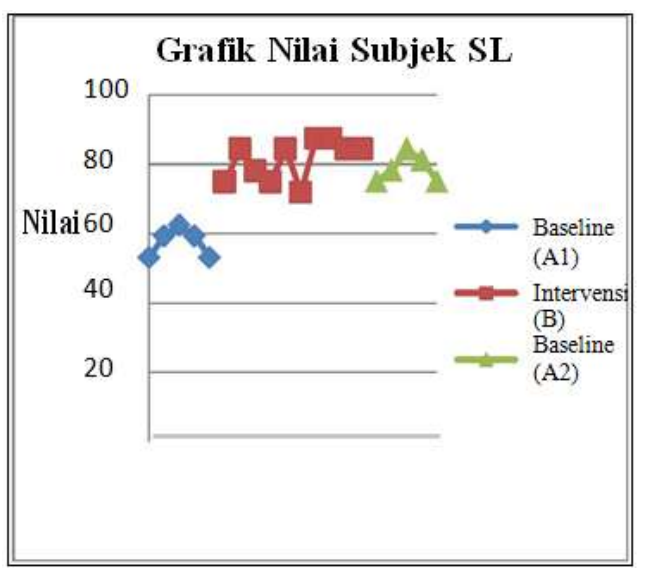

Gambar 1 Grafik Perbandingan Nilai Tahap A1-B-A2

Berdasarkan data Tabel dan Gambar yang diperoleh dari pengukuran Baseline 1, intervensi, dan Baseline 2, menunjukkan bahwa permainan adaptif terbukti dapat meningkatkan kemampuan gerak dasar non lokomotor dalam menggenggam dan merenggangkan jari. Hal ini ditunjukkan dengan rata-rata hasil nilai yang diperoleh Subjek SL pada fase Baseline 1 adalah 57,5, intervensi adalah 81,56, dan Baseline 2 adalah 78,75 .

\section{Pembahasan}

Hasil analisis data menunjukkan bahwa penerapan permainan adaptif pada subjek SL terbukti meningkatkan kemampuan gerak dasar non lokomotor dalam menggenggam dan merenggangkan jari. Peningkatan tersebut dapat dilihat dari meningkatnya kemampuan pada tiap aspek, yaitu aspek menjumput, menggenggam, meremas dan merenggangkan jari pada saat pelajaran.

Penelitian ini dilakukan melalui 3 tahapan yaitu baseline 1, intervensi dan baseline 2. Kondisi baseline 1 menunjukkan kemampuan awal gerak dasar non lokomotor dalam menggenggam dan merenggangkan jari subjek SL setelah dilakukan observasi dengan instrumen yang telah disediakan memperoleh nilai
57,5. Nilai tersebut diperoleh dari lima kali pengamatan oleh 2 penilai. Nilai 57,5 dikategorikan cukup, namun untuk dapat melaksanakan tugas pertumbuhan dan perkembangan pada tingkat mahir, hal tersebut masih kurang dan harus ditingkatkan.

Tahap selanjutnya yaitu pemberian intervensi berupa permainan adaptif yang dilakukan selama sepuluh kali pengamatan. Peneliti menggunakan permainan adaptif agar kemampuan gerak dasar non lokomotor dalam menggenggam dan merenggangkan jari meningkat. Yusuf (2014) pendidikan jasmani adaptif adalah suatu sistem pemberian program dan layanan yang bersifat komprehensif, dirancang untuk mengetahui, menemukan dan memecahkan masalah dalam ranah psikomotor/biomotor (hlm. 5). Pendidikan jasmani adaptif tidak lepas dari aktivitas yang menyenangkan yang biasa dikenal dengan istilah bermain. Menurut Singer, bermain memberikan suatu cara bagi anak untuk memajukan kecepatan masuknya perangsangan (stimulasi), baik dari dunia luar maupun dari dalam yaitu aktivitas otak yang secara konstan memainkan kembali dan merekam pengalaman-pengalaman (Tedjasaputra, 2001:12). Hal itu dapat dikaitan dengan temuan penelitian bahwa salah satu pengaruh bermain terhadap perkembangan anak yaitu meningkatkan perkembangan keterampilan gerak (Hidayatulloh, 2006). Permainan adaptif merupakan wujud modifikasi permainan yang disesuaikan dengan karakteristik siswa.

Permainan adaptif dapat]] meningkatkan kemampuan gerak dasar non lokomotor dalam menggenggam dan merenggangkan jari. Hal tersebut benar jika kemampuan gerak dasar non lokomotor siswa meningkat setelah diterapkan permainan adaptif. Permainan adaptif merupakan wujud modifikasi permainan yang disesuaikan dengan karakteristik] siswa. Berdasarkan hasil pengamatan

Cite this as: peneliti, karakteristik anak tunaganda

Forestry, Silmi, Salim, Abdul, Sunardi. Efforts To Improve Basic Motion Capabilities Non- Locomotor For Double Handicap Student Using Adaptive Game Application. Indonesian Journal of Disability Studies (IJDS).2018: Vol. 5(1): PP 46 - 51 
spectrum tunanetra dan celebral palsy] dengan inisial SL salah satunya yaitu tertarik dengan benda yang dapat menghasilkan bunyi/suara, sehingga media yang digunakan peneliti dalam permainan adaptif yaitu mainan bebek dari bahan karet dan bola yang dapat menimbulkan suara. Fungsi media dalam pembelajaran salah satunya yaitu digunakan untuk melengkapi proses belajar supaya lebih menarik perhatian siswa (Sudjana, 2009: 66). Sehingga ketika permainan adaptif tersebut diterapkan kepada subjek SL, karena ketertarikan subjek dengan media yang digunakan dalam permainan adaptif tersebut maka kemampuan subjek dalam menggenggam dan merenggangkan jari meningkat. Hal ini menjelaskan mengapa permainan adaptif dapat meningkatkan kemampuan gerak dasar non lokomotor pada subjek penelitian.

Permainan adaptif dapat meningkatkan kemampuan gerak dasar non lokomotor dalam menggenggam dan merenggangkan jari hal tersebut dibuktikan ketika proses belajar berlangsung. Apakah dalam pembelajaran subjek melakukan kegiatan secara mandiri, dengan prompting/dorongan, sedikit bantuan atau bantuan penuh yang diberikan nilai dengan interval 1 - 4. Nilai yang didapat dari fase baseline 1, intervensi dan baseline 2 menunjukkan adanya peningkatan sebelum diberikan intervensi dan setelah diberikannya intervensi. Peningkatan tersebut dapat dilihat dari nilai rata-rata pada baseline 1 yaitu 57, 5 dan nilai baseline 2 (setelah diberikan intervensi) yaitu 78, 75 .

$$
\text { Meningkatnya nilai atau }
$$

kemampuan gerak dasar non lokomotor dalam menggenggam dan merenggangkan jari dikarenakan beberapa hal yaitu permainan adaptif merupakan permainan yang dimodifikasi atau diadaptasi sesuai dengan karakteristik subjek sehingga siswa dapat melakukan kegiatan permainan dengan baik karena media yang digunakan merupakan sesuatu yang menarik bagi

subjek. Permainan adaptif juga merupakan wujud pembelajaran yang menyenangkan dan mengasyikkan sehingga subjek dapat mengeksplorasi dirinya tanpa adanya tekanan negatif.

\section{Kesimpulan}

Berdasarkan hasil penelitian dapat penulis simpulkan bahwa permainan adaptif dapat meningkatkan kemampuan gerak dasar non-lokomotor pada siswa tunaganda kelas IV SLB/A YKAB Surakarta. Dengan kemampuan gerak dasar non lokomotor yang baik, anak tunaganda akan lebih mudah beraktivitas. Hal ini berdampak positif pada nilai-nilai maupun aktivitas pembelajaran di sekolah.

\section{DAFTAR PUSTAKA}

Hendrayana, Yudy. (2013). Pendidikan Jasmani dan Olahraga Adaptif (Adapted Physical Education and Sport). Jakarta:Celtics Press

Sudjana, N. (2009). Penilaian Hasil Proses BelajarMengajar. Bandung: RemajaRosdakarya

Sugiyono, (2012). Metode penelitian pendidikan (pendekatan kuantitatif, kualitatif, dan R\&D). Bandung: Alfabeta

Sunanto, Juang., Takeuchi, Koji., \& Nakata, Hideo. (2005). Pengantar Penelitian Dengan Subyek Tunggal. Japan: University of Tsukuba

Supena, Asep. (2014).Pedoman Pembelajaran Pendidikan Jasmani Adaptif bagi Peserta Didik Autis di SMPLB. Jakarta: Universitas Negeri Jakarta

Tedjasaputra, Mayke S. (2001). Bermain, Mainan, dan Permainan. Jakarta: Grasindo

Forestry, Silmi, Salim, Abdul, Sunardi. Efforts To Improve Basic Motion Capabilities Non- Locomotor For Double Handicap Student Using Adaptive Game Application . Indonesian Journal of Disability Studies (IJDS).2018: Vol. 5(1): PP 46 - 51 
Undang-Undang Nomor 20 Tahun 2003 Tentang Sistem Pendidikan Nasional, Pasal 3

Yusuf, Munawir., Choiri, Abdul S., \& Leleno, Joko. (2014) (2014).Pedoman

Pembelajaran Pendidikan Jasmani

Adaptif bagi Peserta Didik SMPLB/MTsLB Tuna Daksa. Surakarta: Pendidikan Luar Biasa. UNS

M. Furqon H. (2006). Mendidik Anak Dengan Bermain. Surakarta:

ProgramD-2 Pendidikan Jasmani. JPOK FKIP UNS 